\title{
Equivalent Thicknesses of Lead and Fly ash Geopolymer with Addition of Barium Sulphate in Radiation Protection
}

\author{
${ }^{1,4}$ Sabri M. Shalbi, ${ }^{1}$ M.S.Jaafar, ${ }^{1}$ Naser M. Ahmed, ${ }^{2}$ A.M. Al-jarrah, ${ }^{1}$ Abdullah. \\ Naji, ${ }^{3}$ M. A. Qaeed \\ ${ }^{I}$ (Medical Physics, School of Physics, Universiti Sains Malaysia, 11800 USM Penang, Malaysia) \\ ${ }^{2}$ (Sharjah Men's College, Higher Colleges of Technology, P.O. Box, Sharjah, United Arab Emirates) \\ ${ }^{3}$ (Physics Department, Faculty of Education, Hodeidah Universiti, Al-Hodeidah, Yemen) \\ ${ }^{4}$ (Higher Institute medical professions khoms and Elmergib University, Libya)
}

\begin{abstract}
This study aims to fabricate radiation protection shields using fly ash with barium Sulphate. Different thickness of fly ash geopolymer with $15 \%$ of barium sulphate was constructed, and different energies of X-ray ranged from $80 \mathrm{kVp}-120 \mathrm{kVp}$ were used to assessment the attenuation ability of Lead and fly ash geopolymer with barium Sulphate shields. Different thicknesses of fly ash based shields are investigated to determine the equivalent thicknesses of fly ash geopolymer with barium sulphate which provide the same attenuation by Lead shields. The results exhibited that $5 \mathrm{~cm}$ of fly ash geopolymer with barium Sulphate equivalent $1 \mathrm{~mm}$ of Lead in attenuating of incident $X$-ray. Whereas $1 \mathrm{~cm}$ of fly ash geopolymer with barium sulphate equivalent $0.25 \mathrm{~mm}$ of Lead shield at various $X$-ray energy ( $80 \mathrm{kVp}-120 \mathrm{kVp}$ ).
\end{abstract}

Keywords: Lead; Fly ash geopolymer; Thickness; $\mathrm{Ba}_{2} \mathrm{SO}_{4}$; Radiation proection

\section{Introduction}

Fly ash is the byproduct of coal combustion. Every year a rough assessment of 600 million tonnes of fly ash generated worldwide [1]. Fly ash is a low-cost material and available to construct the shielding instead of that high-cost materials such as Lead and concrete, also, increasing barium sulphate ratios in fly ash mixture can improve the ability of fly ash based shields in attenuating X-ray [2]. The barium borate - fly ash glasses are better shields to attenuate radiations in comparison to the standard radiation shielding concretes [3]. On the other hand, using cement Portland in X-ray room wall construction has some disadvantages such as the production of Portland cement is consequently one of the largest global sources of combustion and chemical process related carbon dioxide emissions, accounting for $5 \%$ of global carbon dioxide production or approximately 1.5 tonnes per year [4]. Thus, a small reduction of Portland cement production could result in significant environmental benefits in terms of $\mathrm{CO}_{2}$ emission [5]. In addition, there are many drawbacks associated with the usage of concrete, such as considerable variability in its composition and water content. This variation results in uncertainty in calculations for shield design predictions of the radiation distribution and attenuation in the shield. Water contents have the disadvantages of decreasing both density and structural strength of concrete [6]. One possible alternative is the use of alkali-activated binders using fly ash. The current trend in the construction industry is leaning more towards sustainable practices every year, making research valuable by providing a means to limit waste and recycle material [4]. An added benefit is to convert a waste product into a useful byproduct radiation protection shields. For radiation shielding, a larger quantity of shielding material is required; therefore, the study of a propagation of radiation flux in shielding materials is an essential requirement for shield design [7]. So, this study aims to fabricate the thickness of (fly ash geopolymer with barium Sulphate) which equivalent to the thickness of Lead needed for protection against incident X-rays generated by X-ray tube voltage between 80 and $120 \mathrm{kVp}$.

\section{Materials}

The materials were utilized in this study including x-ray machine as a source of radiation exposure, dosimeter consists of calibrated ion chamber and electrometer, fly ash with barium sulphate and Lead shields with different thicknesses as it shown in Figure 1. 


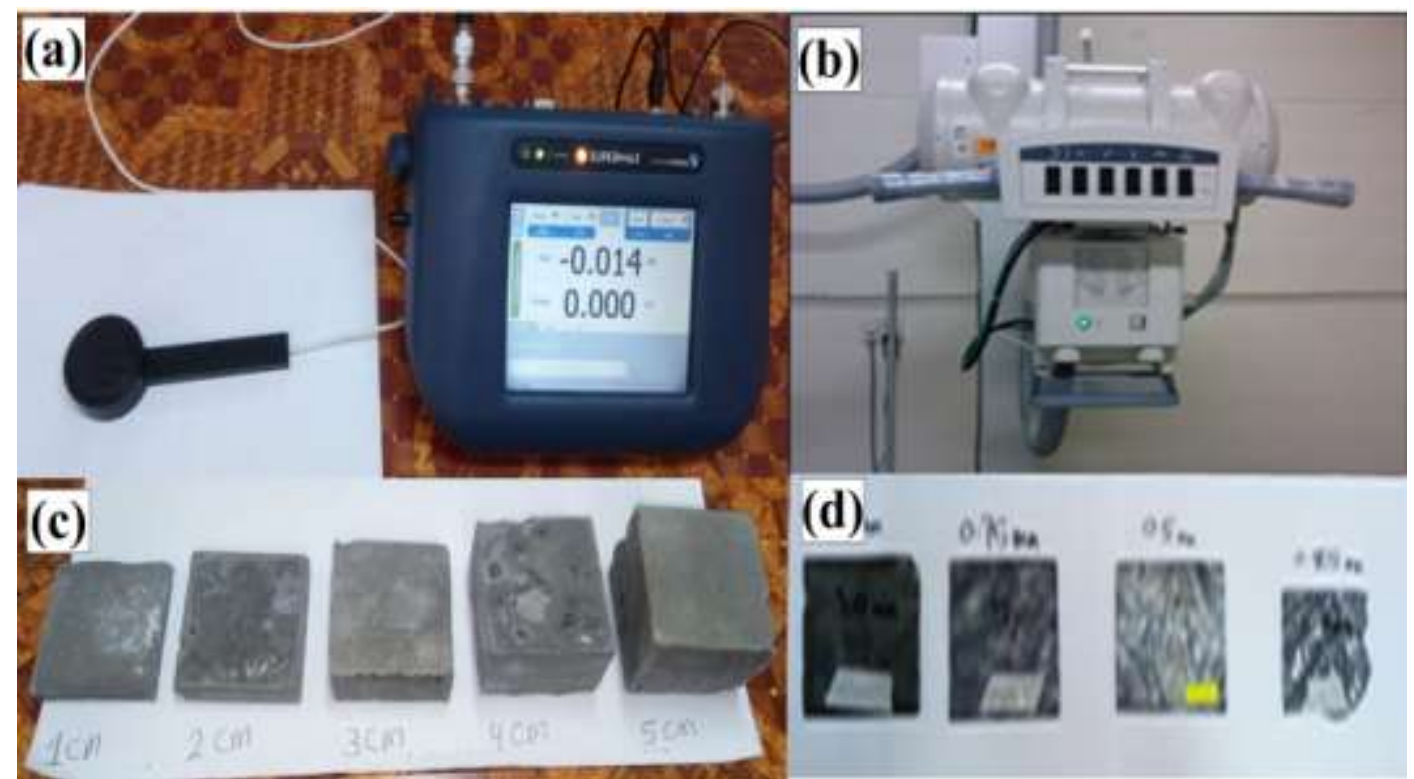

Figure 1: The Materials utilized in this study; (a) Ion chamber and electrometer, (b) X-ray source, (c) Fly ash with $15 \%$ of barium Sulphate shields with different thicknesses, (d) Lead shields with different thicknesses.

\section{Method}

Different thicknesses of fly ash with $15 \%$ of barium sulphate shields were investigated to assess its ability in attenuating X-ray comparing to Lead shields, the penetrating dose through Lead and fly ash based shields were recorded and analysed to determine equivalent thicknesses of fly ash shields to achieve attenuation as equal as Lead shields. The setup of experimental measurement illustrated in Figure 2.

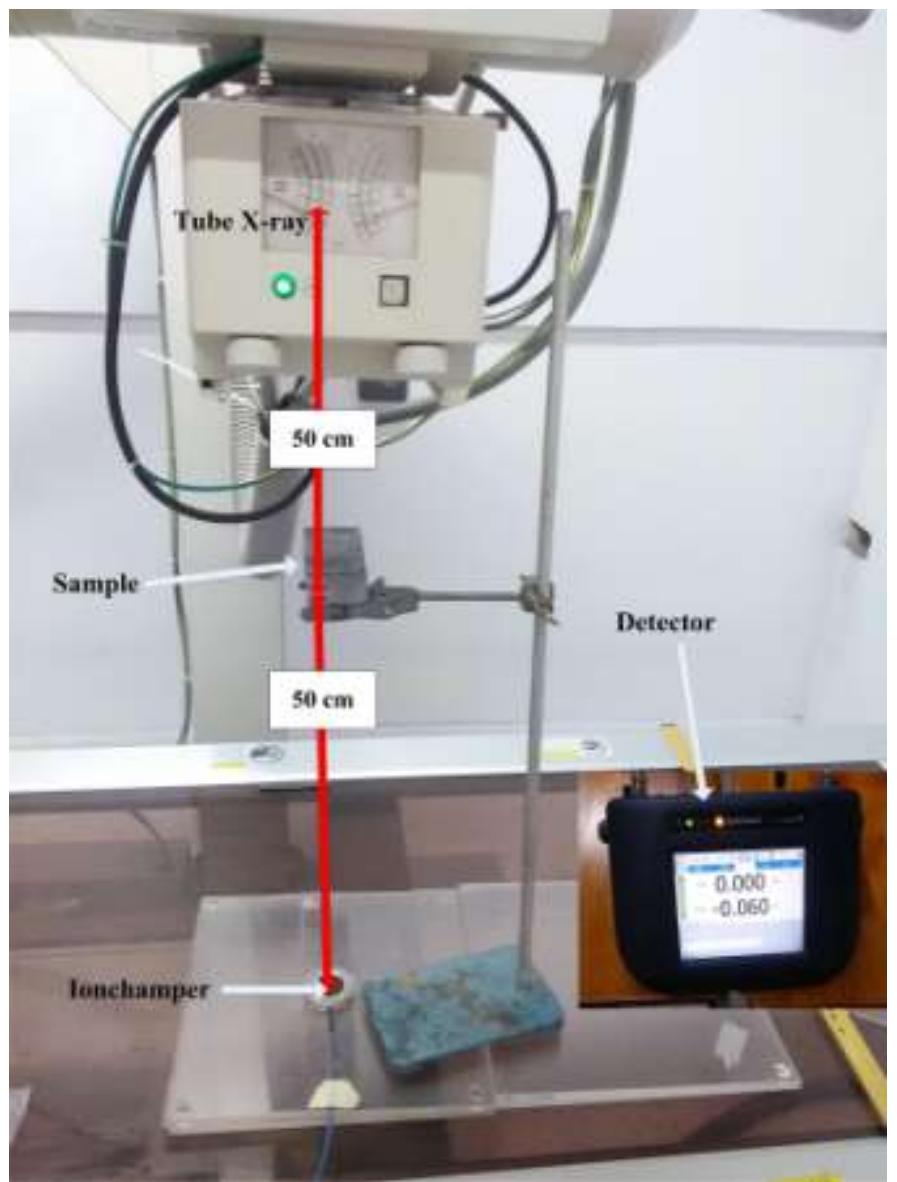

Figure 2: Experiment set up 


\section{Results and discussions}

\section{Comparison between Lead and fly ash $+15 \% \mathrm{BaSO}_{4}$ in attenuating $\mathrm{X}$-ray $(80 \mathrm{kVp})$}

The results of this part show the differences between Lead and fly ash, including $15 \%$ of barium sulphate shields, Figure 3 shows that, the attenuation of X-ray increase by increasing shield thickness. Fly ash with barium sulphate can achieve the same X-ray attenuation comparing to Lead but with different thickness, 1 $\mathrm{cm}$ thickness of fly ash geopolymer with $15 \%$ of barium sulphate can attenuate X-ray more than $0.25 \mathrm{~mm}$ of the Lead shield. Also, $3 \mathrm{~cm}$ shield thickness of fly ash geopolymer with $15 \%$ of barium sulphate equalize the attenuation capability of $0.75 \mathrm{~mm}$ shield thickness of Lead, whereas the $5 \mathrm{~cm}$ shield thickness of fly ash geopolymer with $15 \%$ of barium sulphate equalizes the attenuation capability of $1 \mathrm{~mm}$ shield thickness of Lead.

Figure captions appear below the figure, are flush left, and are in lower case letters. When referring to a figure in the body of the text, the abbreviation "Fig." is used. Figures should be numbered in the order they appear in the text.

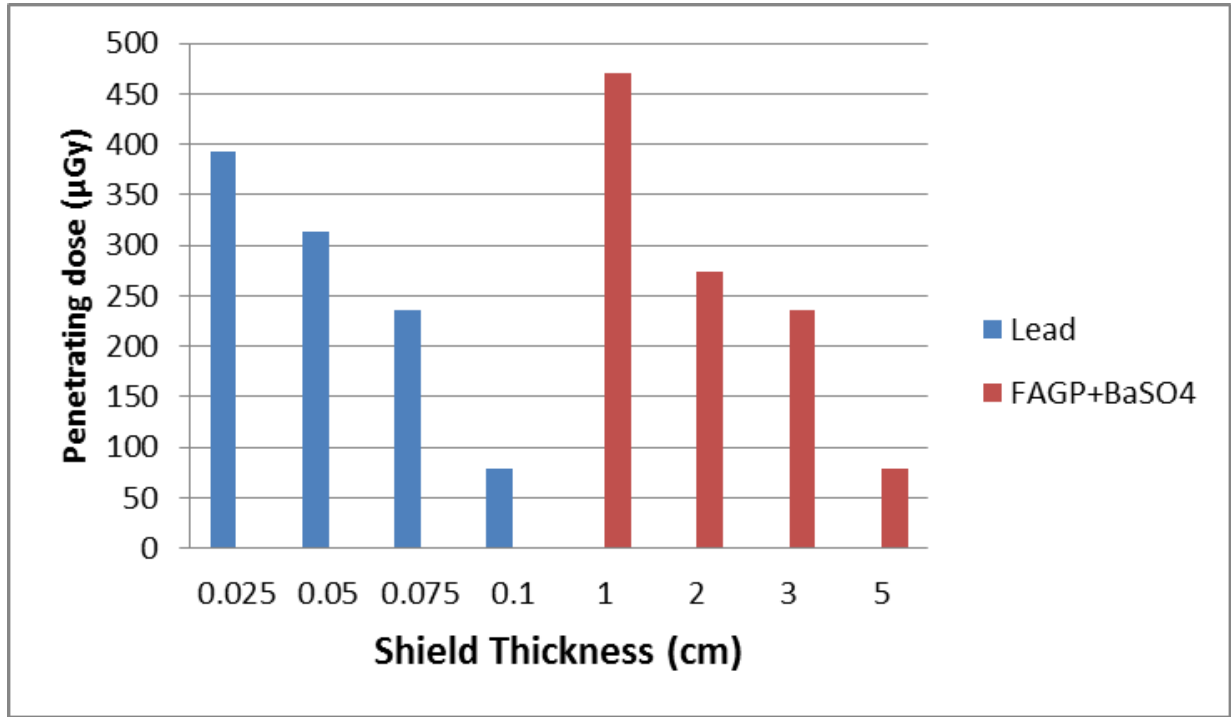

Figure 3: Attenuation of X-ray by Lead and fly ash with $15 \%$ barium sulphate at $80 \mathrm{kVp}$

To present the ability of different thicknesses of Lead and fly ash with barium sulphate shields the percentage of radiation attenuation through these shields are calculated and illustrated in Figure 4, the attenuating percentage of all utilized thicknesses are more than $80 \%$, and the attenuating percentage increase by increasing shield thickness and reach to 97.11 with $5 \mathrm{~cm}$ of fly ash geopolymer with $15 \%$ of the barium sulphate shield. This result is consistent with an earlier result by Bari et al., (2015), who reported that an increase in peak tube voltage leads to higher X-ray penetration through X-rays room shields.

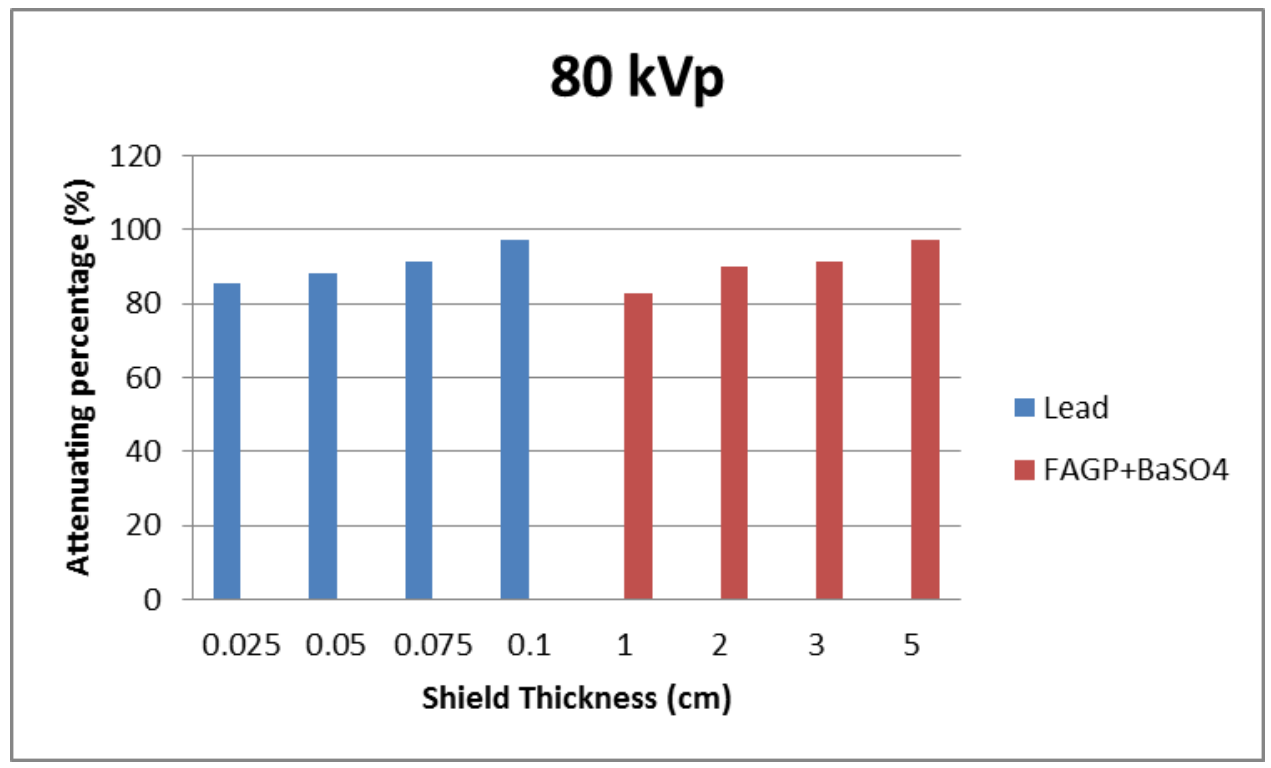

Figure 4: The effect of fly ash based shield thickness on attenuation of incident X-ray 


\section{Comparison between Lead and fly ash geopolymer $+15 \% \mathrm{BaSO}_{4}$ in attenuating $\mathrm{X}$-ray at $100 \mathrm{kVp}$}

Incident photons energy increase by increasing X-ray tube voltage and the penetrating dose through lead and fly ash shields increase Figure 5 shows that $5 \mathrm{~cm}$ and $3 \mathrm{~cm}$ of fly ash geopolymer with barium Sulphate shields equalized $1 \mathrm{~mm}$ and $0.75 \mathrm{~mm}$ of Lead shields respectively.

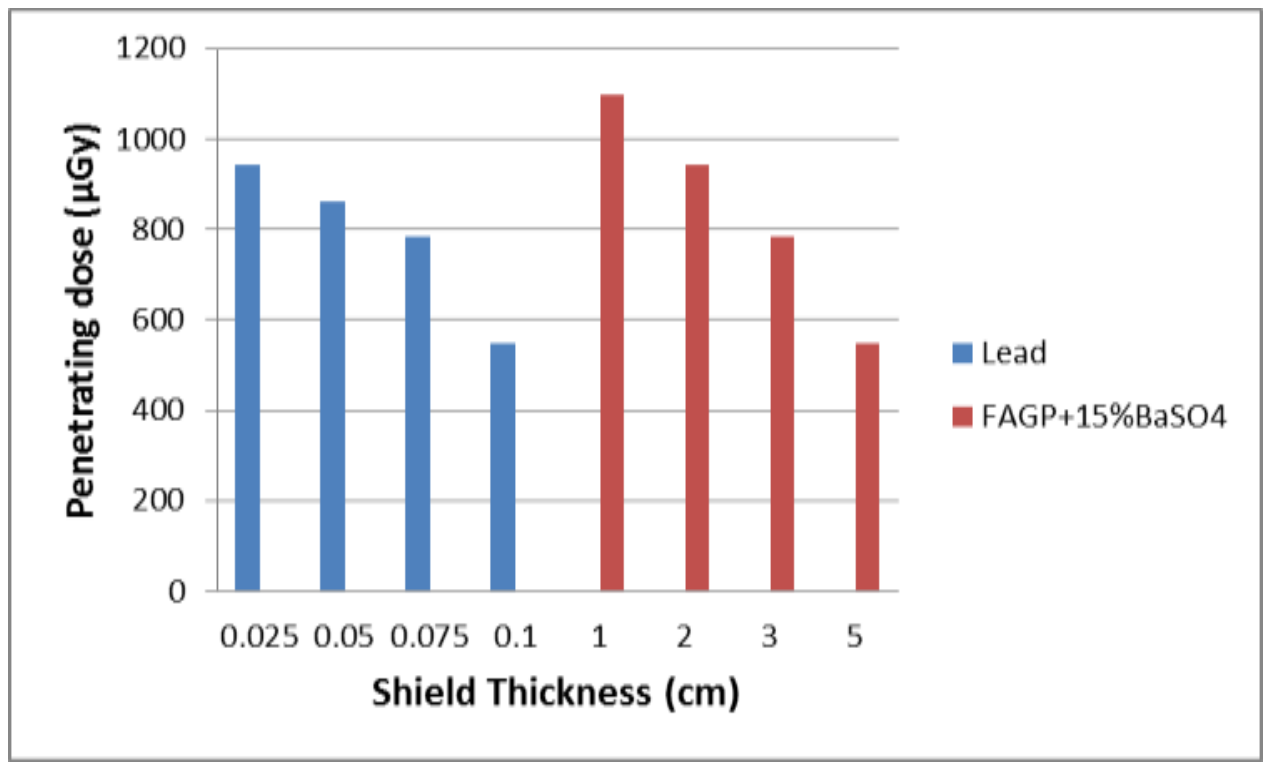

Figure 5: Attenuation of X-ray by Lead and fly ash geopolymer with $15 \%$ barium sulphate at $100 \mathrm{kVp}$

The results show that the penetrating dose increase by increasing incident photons energy and decreasing shield thickness for both investigated materials (Lead and fly ash geopolymer with barium sulphate). To compare the capability of different thicknesses for both materials shields the percentage of attenuating are calculated and presented in Figure 6, the results exhibited that more attenuating percentage can be achieved by thicker shields, the attenuating percentage reach to $86.93 \%$ for $5 \mathrm{~cm}$ shield of fly ash geopolymer with $15 \%$ barium sulphate based shield and its equivalent thickness from Lead shield ( $1 \mathrm{~mm}$ thickness of Lead).

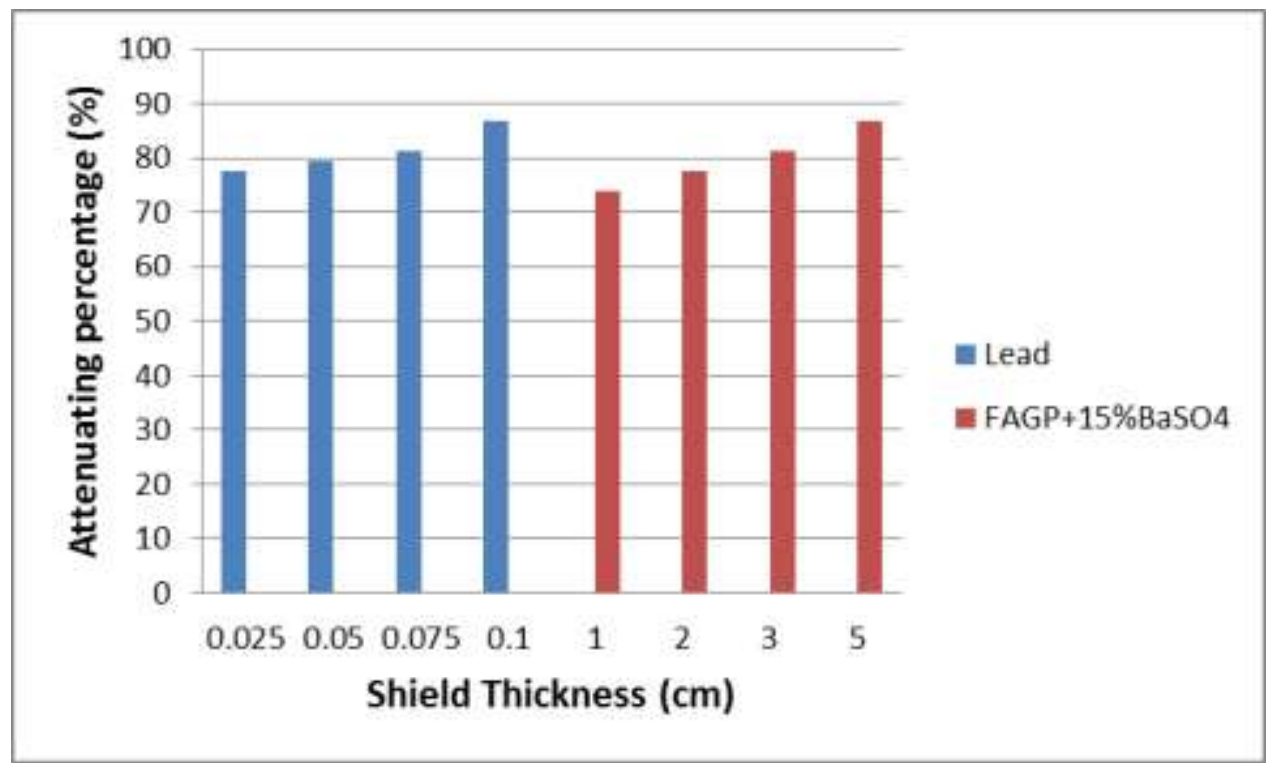

Figure 6: The effect of fly ash based shield thickness on attenuation of incident X-ray

\section{Comparison between Lead and fly ash geopolymer with $15 \% \mathrm{BaSO}_{4}$ in attenuating $\mathrm{X}$-ray at $120 \mathrm{kVp}$}

At high X-ray energy $(120 \mathrm{kVp})$, the results exhibited more transmitting radiation through shields at different thicknesses, $5 \mathrm{~cm}$ thickness of fly ash with $15 \%$ barium sulphate equalized $1 \mathrm{~mm}$ of Lead in attenuating high X-ray energy $(120 \mathrm{kVp})$. Also, $1 \mathrm{~cm}, 2 \mathrm{~cm}$, and $3 \mathrm{~cm}$ of fly ash with $15 \%$ of barium sulphate based shields equivalent $0.25 \mathrm{~mm}, 0.5 \mathrm{~mm}$, and $0.75 \mathrm{~mm}$ of Lead shields respectively as shown in Figure 7 . 


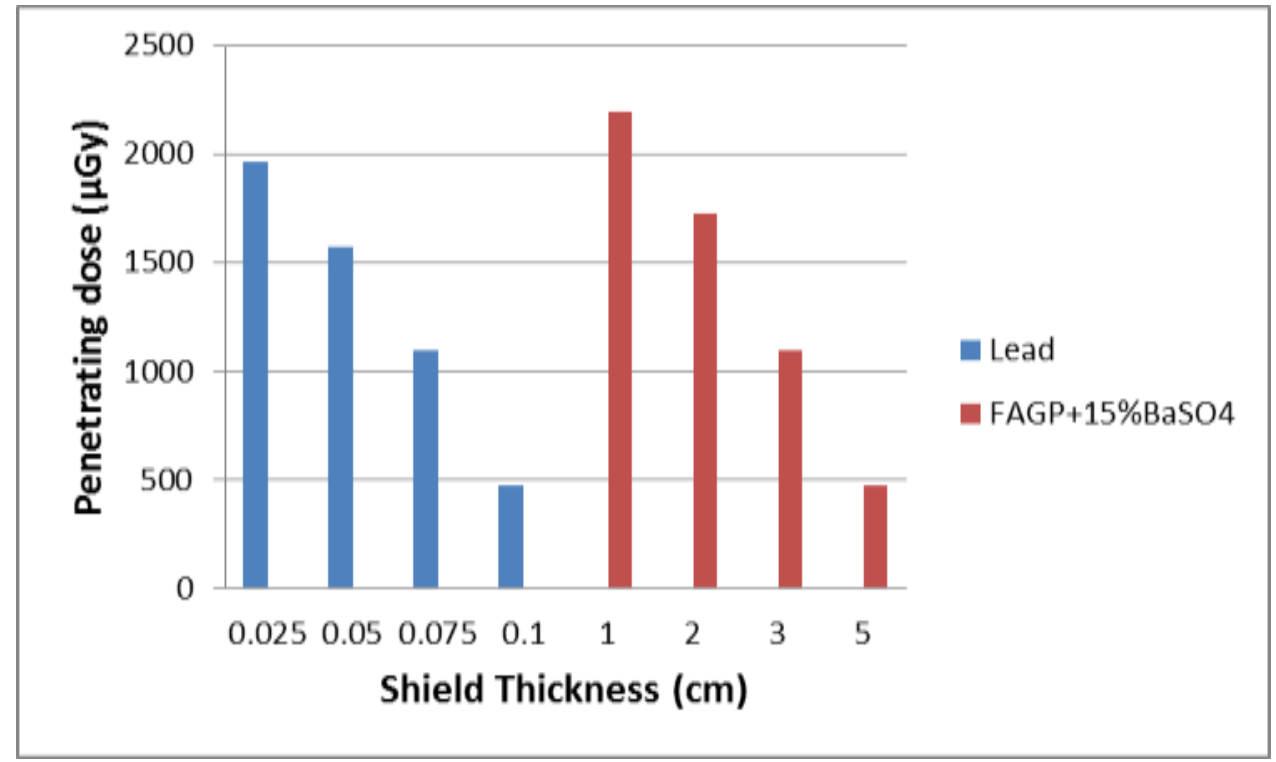

Figure 7: Attenuation of X-ray by Lead and fly ash with barium sulphate at $120 \mathrm{kVp}$

To determine the capability of different thicknesses of shields in attenuating incident X-ray the attenuating percentage of shields are calculated and illustrated in Figure 8, the results showed that by increasing $\mathrm{X}$-ray tube voltage the penetrating power of incident X-ray photons increase and the attenuating ability of shields somewhat decrease, although the attenuation of radiation by fly ash based shields increase by increasing shield thickness, the optimum attenuation recorded for $5 \mathrm{~cm}$ thickness of fly ash geopolymer with $15 \%$ barium sulphate shield up to $91.55 \%$ at high X-ray energy $(120 \mathrm{kVp})$.

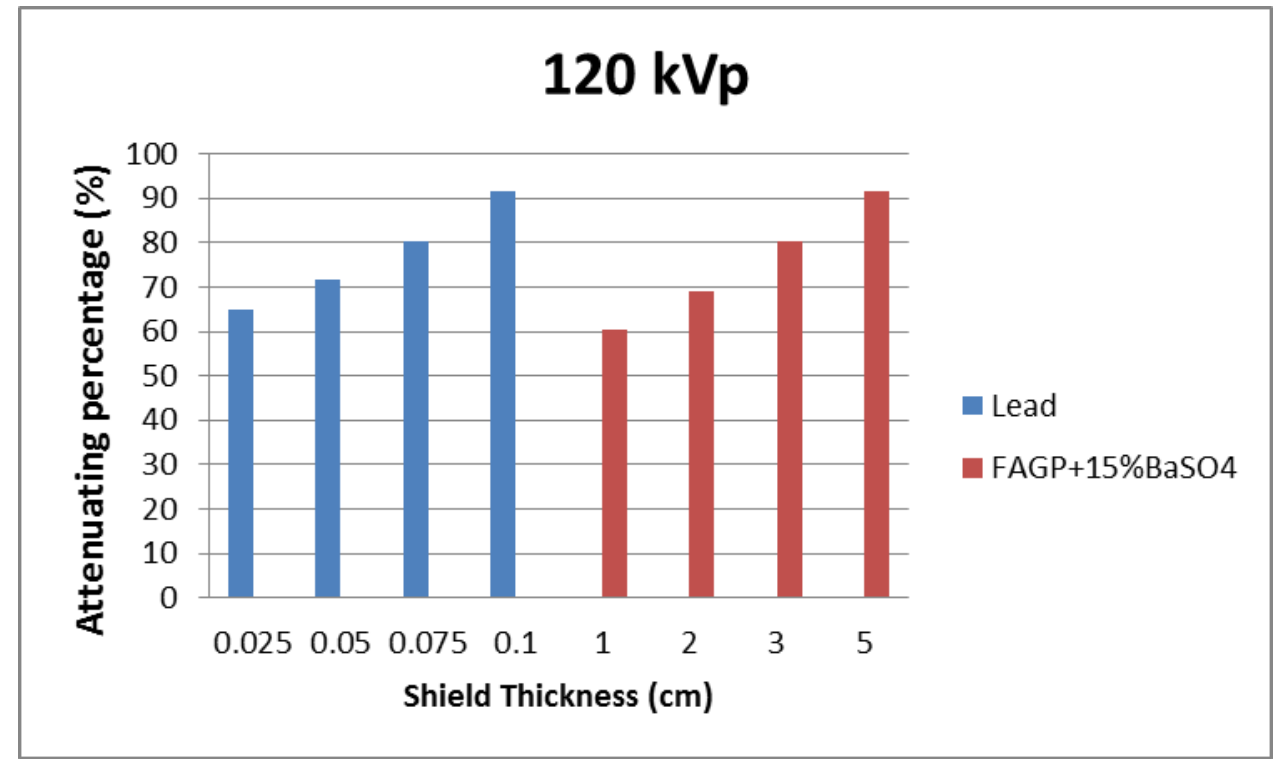

Figure 8: The effect of fly ash based shield thickness on attenuation of incident X-ray

This result is consistent with the study by Hohl et al., (2005) who reported that with a $1 \mathrm{~mm}$ Lead shield and scanning parameters of $120 \mathrm{kVp}, 50 \mathrm{~mA}, 0.5 \mathrm{sec}$, and $0.15 \mathrm{~m}$, an $87 \%$ reduction of radiation dose released during routine abdominopelvic scan was achieved [8].

\section{Conclusion}

Fly ash geopolymer with $15 \%$ barium Sulphate based shields presented good ability in attenuating incident X-ray and can be used instead of Lead and concrete in constructing X-ray room walls and shields, the capability of fly ash based shields can be improved by adding barium sulphate to fly ash batch, also more attenuation for X-ray can be achieved by increasing the thickness of fly ash shields. The low cost and availability of fly ash as well as, environment safety make fly ash with $15 \%$ barium sulphate based shields as the best choice for radiation protection industry. 


\section{Acknowledgements}

I wish to thank Universiti Sains Malaysia for supporting this work, special thank goes to Prof. Dr. Mohamad Suhaimi Jaafar for his feedback and comments, Also Higher Institute medical professions khoms and Elmergib University, of Libya for awarding the scholarship to assist my pursuit of a $\mathrm{PhD}$.

\section{References}

[1]. Sambyal, P., et al., Designing of MWCNT/ferrofluid/flyash multiphase composite as safeguard for electromagnetic radiation.

[2]. K, O., A.A.-k. K, and s. S, Barium Sulfate Epoxy Mixture Effects on Attenuation of Short Wavelength. Radiation Nuclear and Radiation Physics, 2010. 80: p. 31333-31338.

[3]. Singh, S., et al., Barium-borate-flyash glasses: as radiation shielding materials. Nuclear Instruments and Methods in Physics Research Section B: Beam Interactions with Materials and Atoms, 2008. 266(1): p. 140-146.

[4]. Kotwal, A.R., et al., Characterization and early age physical properties of ambient cured geopolymer mortar based on class C fly ash. International Journal of Concrete Structures and Materials, 2015. 9(1): p. 35-43.

[5]. Gunasekara, M., D. Law, and S. Setunge, Effect of composition of fly ash on compressive strength of fly ash based geopolymer mortar. 2014.

[6]. Bootjomchai, C., et al., Gamma-ray shielding and structural properties of barium-bismuth-borosilicate glasses. Radiation Physics and Chemistry, 2012. 81(7): p. 785-790.

[7]. Singh, N., et al., Comparative study of lead borate and bismuth lead borate glass systems as gamma-radiation shielding materials. Nuclear Instruments and Methods in Physics Research Section B: Beam Interactions with Materials and Atoms, 2004. 225(3): p. 305-309.

[8]. Hohl, C., et al., Radiation dose reduction to the male gonads during MDCT: the effectiveness of a lead shield. American Journal of Roentgenology, 2005. 184(1): p. 128-130. 